\title{
Are we making a difference? Rural university students' perceptions of diversity and inclusion
}

\author{
Henry Wai Leong Ho \\ Ferris State University \\ Catherine S. Browers \\ Ferris State University
}

\begin{abstract}
Recent demographic trends indicate that the evolving workforce will increasingly comprise a variety of cultures, belief systems, and ethnic populations. As future professionals in a global environment, post-graduate business students must understand the increasing importance of differences they will encounter. The purpose of this study is to understand business students' perceptions of diversity and inclusion during their academic experience in a rural university in west-central Michigan, USA. The research design was descriptive, and the research was conducted using a quantitative method of surveying. Any students currently pursuing their qualification at College of Business comprised the target population. A total of 349 students responded to the survey. The respondents ranging in age from 18-24 years responded to Likert scale and nominal questions regarding their perceptions on diversity and inclusion. Although mostly positive, business students shared that some of the current programs could be improved. These perceptions provide constructive data for use in evaluating and amending current diversity and inclusion programs and suggestions for future research are offered based on the study's findings.
\end{abstract}

Keywords: Higher education, USA, rural university, diversity and inclusion, students' perceptions

\section{Introduction}

As instructors in the College of Business (COB), we are charged with the task of providing our students with the best of our knowledge and expertise in order to prepare them for the future. At our university, this goes beyond the traditional application of textbook reading and classroom lectures; we also provide our students with knowledge and exposure to practical application of course learning.

Corresponding author: Henry Wai Leong Ho (henryho@ferris.edu) 
One area of great emphasis in the COB is students' ability to work effectively in a team environment. This draws in many areas of business understanding and competency at our college, such as organizational culture, emotional intelligence, leadership theory, and global awareness. The last point, global awareness, has at its root the concepts of diversity and inclusion, and underscores the reality of our multicultural world society. Consequently, students seeking future success in their post-graduate experience must have an understanding of the nuances of diversity and inclusion in their present and future business environments.

As we are a rural university in west-central Michigan, we often wonder how much understanding our students have of diversity and inclusion. Several of our business students come to us from rural backgrounds and may struggle to have a practical understanding of differences in the populations they will encounter in the future. We felt it was important to find out if their experience as a university student in the COB gave them a greater awareness of the importance of their role in a global culture.

\section{Literature Review}

Quite often, diversity and inclusion are identified with just the word, "diversity". However, a number of perceptions exist for defining diversity and inclusion as different constructs. Roberson (2006) suggests that a significant difference exists between these two concepts, which is supported by other researchers (Green, Lopez, Wysocki \& Kepner, 2002). Diversity is defined as understanding the differences that exist between people in regards to age, class, ethnicity, gender, physical and mental ability, race, sexual orientation, spiritual practice, public assistance status, and other social variables (Etsy, Griffin \& Schorr-Hirsh, 1995; Hakkola \& Ropers-Hullman, 2018). Inclusion, on the other hand, takes that understanding a step further. Once diversity understanding is achieved, inclusion promotes a "sense of belonging, feeling respected... [and receiving] supportive energy from others" (Miller \& Katz, 2002, p. 147). It goes beyond knowledge to ascribe value to an individual.

For the past few decades, researchers have conducted studies to explain the importance of diversity and inclusion education within the university community. Most of the available literature on this topic indicates that a diverse student body leads to frequent, meaningful interaction for all students (Chang, Astin \& Kim, 2004; Chang, Denson, Saenz \& Misa, 2006; Hurtado, Milem, Clayton-Pedersen \& Allen, 1998; Smith, 2015). A diverse student population enables colleges to provide students with skills and abilities that will presumably prepare them for post-graduate experiences (Hakkola \& Ropers-Hullman, 2018; Jayakumar, 2008). With this in mind, an increased interest now exists in higher education to produce diverse, competent citizens who can be leaders in a global marketplace (Brint, 2015). Universities have an important role to play in ensuring that the next generation of employees is prepared for the growing challenges of an increasingly diverse global work force (Sumner, Sgoutas-Emch, Nunn \& Kirkley, 2017). The significance of this cannot be ignored. According to Mor Barak, Cherin and Berkman (1998), the increased level of secondary education attainment in developed countries has become a global phenomenon, resulting in the reality of an increasingly diverse work force. This, in conjunction with worldwide population growth, provides justification for increased diversity and inclusion education for university students (Norman, Chang \& Prieto, 2017).

The continued interest of universities to promote student diversity and inclusion sensitivity in the business world is equally matched by employer requirements due to rising differences in global population (Green et al., 2002). In particular, business students who are preparing for their post-graduate professional careers require opportunities for exposure to increasing 
changes in global demographics, cultural perspectives, and economic evolution (Kwak, Gavrila \& Ramirez, 2019; Mor Barak, 2014). Effective education programs at the higher education level, which is the final step of preparation for students, can address the existing diversity and inclusion information gaps that these future business professionals will need to master.

Ultimately, the question is how do we identify these knowledge gaps? How do we, as educators, know what information students are lacking to be successful in a diverse work force? At this point, there is minimal literature available focusing on our collective understanding of university students' perceptions of diversity and inclusion education in higher education. For example, Brunner (2006) performed a qualitative inquiry that evaluated the perceptions of students regarding the impact of diversity initiatives on the university community. The focus of the study was to learn if students thought their university was successful in creating a diverse and inclusive campus environment. Managuio (2013) performed a quantitative analysis to identify diversity trends at a large university. His focus was to determine university students' perceptions of diversity and inclusion. His study revealed differences between formal definitions of diversity, inclusion, and student survey perceptions. Differences also existed between college program objectives and survey results. Both of these studies recruited student participants from the total university population, as opposed to a smaller population such as the COB. The lack of research on these issues points towards an opportunity to pursue more investigation.

\section{Objective and hypothesis of the study}

The foundation of our objective and hypothesis originated from our association with the Committee on Inclusion $(\mathrm{Cl})$ in the $\mathrm{COB}$. The $\mathrm{Cl}$ shared their interest in this topic as a result of feedback from business students' perceptions regarding the current COB role in diversity and inclusion initiatives. Consequently, the necessity of a research topic to investigate these perceptions, evolved into a study, developed to evaluate the effectiveness of current diversity and inclusion and evaluate a more effective program.

To address our knowledge gaps, we approached the research by identifying three objectives for this research project. First, it was necessary to determine business students' perceptions of diversity and inclusion. Without that understanding, further efforts to support other inquiries would lack the proper foundation to interpret the data.

Second, we wanted to identify the diversity initiatives that have had the most impact on business students' perceptions. This was the logical hypothesis to follow our first objective. Identifying student perceptions of diversity and inclusion correlated with COB initiatives held for students. Finally, we wanted to discover diversity and inclusion topics that interest business students. Our third hypothesis was a natural progression of objectives to respond to our preliminary knowledge gaps for this study. Results from our research gave us the opportunity to see through a new lens to better understand business students' perceptions of diversity and inclusion, as well as provide information to customize current programs that are better tailored to student needs and interests.

This study proposes three hypotheses related to the research objectives:

$\mathrm{H} 1$ : COB Students who have studied for over two years will tend to agree that College of Business is Diverse.

$\mathrm{H} 2$ : There is a significant relationship between the respondent's profiles and whether they have done any work (within $\mathrm{COB}$ ) on diversity and inclusion areas.

$\mathrm{H} 3$ : There is a significant relationship between the gender of the respondent and the $\mathrm{COB}$ as 
supportive of diversity and inclusion initiatives.

\section{College of Business at Ferris State University}

The students who participated in this research were enrolled in one of the university degrees offered by the College of Business (COB) at Ferris State University (FSU) in Michigan, USA. FSU is a public institution that was founded in 1884 and has eight colleges, with its main campus located in Big Rapids and 19 off campus sites throughout the state (Ferris State University, n.d.). The university is a medium sized comprehensive higher education institution in the United States with more than 14,000 students currently pursuing their university degrees.

As of Fall semester 2015, there were approximately 2657 students pursuing their university qualification at COB (The Ferris State University, n.d.). In brief, COB provides career-oriented education, responding for over 100 years to the changing needs of the business world. Today, with more than 80 full-time faculty, an administrative staff, and a student body numbering in the thousands, the College offers over forty certificate, associate, bachelor's, and master's degree programs to a variety of traditional and nontraditional students at times and locations that are convenient to them (College of Business, n.d.).

\section{Methodology}

The research was conducted using a quantitative method of surveying via SurveyMonkey. A descriptive research design was suitable for this study as it frequently uses data collection methods such as questionnaire survey that involves "asking respondents structure questions about what they think, feel and do" (Hair, Celsi, Ortinau \& Bush, 2017, p. 109). Some benefits of using an online survey are to make sure that the responses were gathered in a standardized way (Ho, 2017) and large amounts of information can be collected from a large number of respondents in a short period of time and a relatively cost-effective way (Hair, et al., 2017).

\section{Sample Size}

In order to determine a representative sample size from our study population, we have adopted Yamane's (1967) approach to identify the right sample size for the survey since his proposal is commonly accepted by many social science researchers for over four decades (see Babin \& Zikmund, 2016; Hair et al., 2017; Israel, 1992; Sarmah, Hazarika \& Choudhury, 2013; Silver, Stevens, Kernek, Wrenn \& Loudon, 2016; Singh \& Masuku, 2014). In brief, Yamane (1967) argued that although a larger sample group can yield more accurate study results, the excessive responses can also be pricey. Hence, predetermined margin of error and level of confidence should be used to determine a representative sample size. In brief, the 95 percent confidence level is suggested for most research (Silver, et al., 2016). For our research project, a sample of 336 participants was considered appropriate for the population being studied (population size: 2657, confidence level: $95 \%$ and margin of error: $5 \%$ ) as indicated in the Survey System's Sample Size Calculator (Creative Research Systems, n.d.).

\section{Research Instrument and Variables}

The questionnaire was designed by the authors formulated on the basis of thorough review of literature and after detailed discussions with the members of the $\mathrm{COB} \mathrm{Cl}$. The final questionnaire consisted of 15 items for assessing students' perceptions of a wide range of diversity and inclusion issues pertaining to their experiences at COB. Students' responses to various survey questions formed the basis for all of the variables used in the analysis. As 
shown in Figure 1, a fishbone diagram (Zikmund, D'Alessandro, Winzar, Lowe \& Babin, 2014) was adopted to explain the dependent variable and independent variables of the study.

\section{Figure 1: A fishbone diagram for perceptions of diversity at the College of Business}

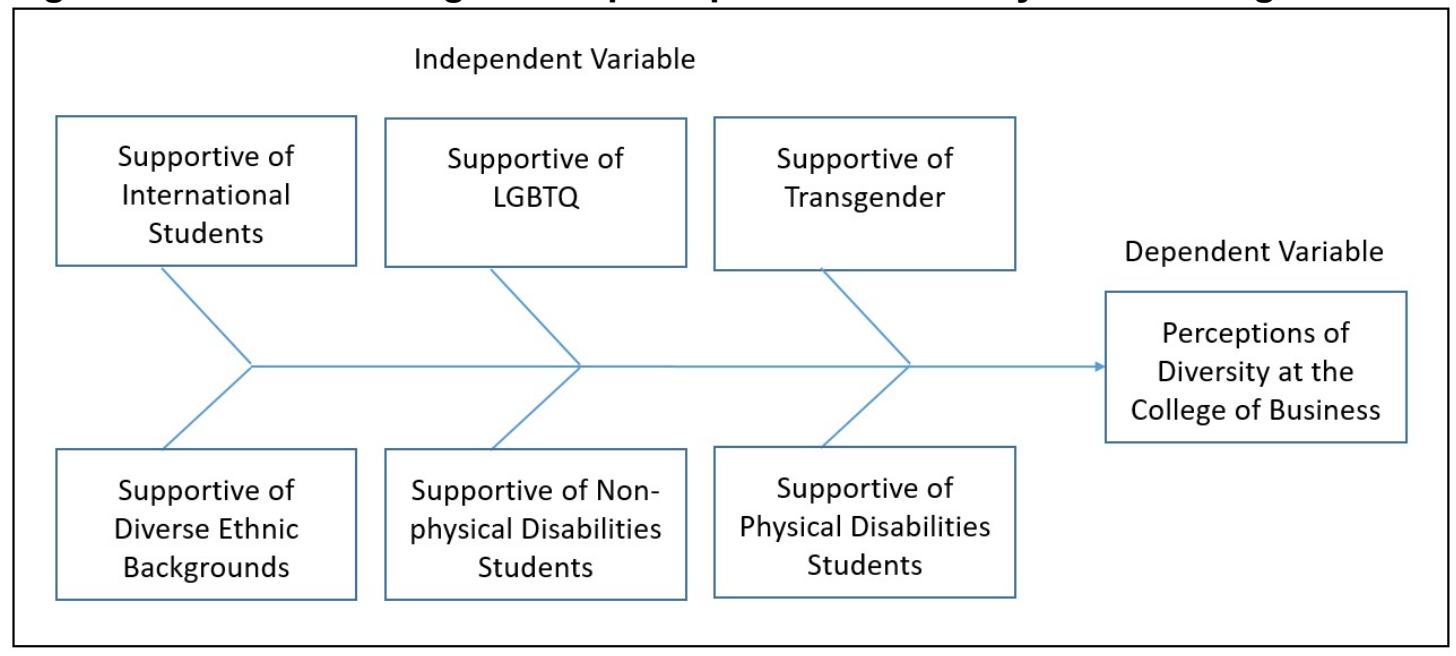

Source: Adopted from Zikmund, et al. (2014)

The questionnaire was separated into three sections. The first section of the questionnaire sought information related to demographics of the participants. Perceptions of students regarding diversity and inclusion within the COB were assessed in the second section of the questionnaire. Five-point Likert Scales was used in the survey questions (i.e. $1=$ Strongly Disagree, 2 = Disagree, $3=$ Neutral, $4=$ Agree \& $5=$ Strongly Agree) of this section to measure students' viewpoints of the diversity initiatives that have had the most impact on our business students and to determine those diversity topics that have been overemphasized in our campus programs. Two open ended questions were then implemented in the third section to end the survey. This section was used to gather students' opinions on how to make them feel included within the COB community as well as challenges encounter in making progress on diversity and inclusion within the college.

\section{Data Collection and Analysis}

The target population of the research consisted of all students who currently pursuing their qualification at COB; the study population consisted of 2657 students (based on the number of enrolled students at COB as of 2016 Fall semester). The survey was administered from September 5 to September 8, 2017 (everyday between 8:30 AM - 4:30 PM), through mallintercept approach. Target respondents were intercepted in a common area (next to Starbucks Café) inside the building of $C O B$ in-order to reach a large segment of the population. The process involved randomly intercepting the students, screening them for appropriateness, and inviting them to complete the survey (via Survey Monkey) on the sport with the laptops make available by the researchers.

Data collected was exported from SurveyMonkey and analyzed in Statistical Package for Social Sciences 24.0 (SPSS 24.0). Descriptive statistics of demographic information and perceptions were determined. Chi square test was used to examine putative associations between perceptions and demographic variables. Apart from quantitative results, students' qualitative feedback regarding diversity and inclusion within the college was also presented in 
the next section.

Apart from several questions on demographics, the majority of questions in the survey were focused on students' perceptions of diversity and inclusion at the COB. Five-point Likert Scales was used in some of the survey questions to measure students' viewpoints of the diversity initiatives that have had the most impact on our business students and to determine those diversity topics that have been overemphasized in our campus programs. All other questions were either nominal or open ended.

\section{Results}

A total of 349 students responded to the survey. The opening questions asked respondents to state their age, gender and current standing at FSU. The results showed that almost all respondents (91.33\%) were between 18-24 years of age. Gender of respondents was slightly unevenly distributed, with $46.82 \%$ indicated for female, $52.31 \%$ male and $0.87 \%$ of transgender. Current standing at FSU, revealed $8.65 \%$ of the respondents considered themselves as Freshman follow by $22.48 \%$ of Sophomore, $28.24 \%$ of Junior and $40.63 \%$ of Senior at FSU.

Respondents were asked to indicate their level of agreement with the statements as shown in Table 1. The intention of these questions was to establish the students' viewpoint of diversity at the $\mathrm{COB}$ (COB). In general, the students claimed that $\mathrm{COB}$ is diverse (i.e. q1 mean is 4.01). Students also claimed that $\mathrm{COB}$ is accessible to and/or supportive of people with different background (q4-q10). However, in response to the statement, "I take advantage of the opportunities that COB provides to learn more about diversity-related issues", 92 (26.59\%) students disagree with the statement and a further $129(37.28 \%)$ were neutral.

Table 1: Students' perceptions of diversity at the College of Business

\begin{tabular}{|c|c|c|c|}
\hline No. & Statement & Mean & $\begin{array}{c}\text { Std. } \\
\text { Deviation }\end{array}$ \\
\hline 1 & College of Business (COB) is diverse. & 4.01 & 0.87800 \\
\hline 2 & I personally add to the diversity of my campus. & 3.33 & 1.22089 \\
\hline 3 & $\begin{array}{l}\text { I take advantage of the opportunities that COB provides } \\
\text { to learn more about diversity-related issues. }\end{array}$ & 3.10 & 1.095 \\
\hline 4 & COB is accessible to people with physical disabilities. & 3.76 & 0.97582 \\
\hline 5 & $\begin{array}{l}\text { COB is supportive of people who identify as lesbian, } \\
\text { gay, bisexual, or queer. }\end{array}$ & 3.65 & .89664 \\
\hline 6 & $\begin{array}{l}\text { COB is supportive of people who identify as } \\
\text { transgender. }\end{array}$ & 3.53 & 90760 \\
\hline 7 & $\begin{array}{l}\text { COB is supportive of people with diverse ethnic } \\
\text { backgrounds. }\end{array}$ & 3.85 & .92530 \\
\hline 8 & COB is supportive of international students. & 3.97 & .90721 \\
\hline 9 & $\begin{array}{l}\text { COB is supportive of students with non-physical } \\
\text { disabilities (e.g., learning disabilities, Attention Deficit } \\
\text { Disorder). }\end{array}$ & 3.71 & .96537 \\
\hline
\end{tabular}




\begin{tabular}{|c|l|c|c|}
\hline 10 & $\begin{array}{l}\text { COB is supportive of people with psychological } \\
\text { disabilities (e.g., anxiety disorders, mood disorders, } \\
\text { depression, and bipolar disorder). }\end{array}$ & 3.48 & .99038 \\
\hline
\end{tabular}

(Five-point Likert scale with $1=$ disagree strongly and $5=$ agree strongly), $N=349$

In order to meet the aforementioned research objectives, the following hypotheses were tested along with their respective results.

H1: COB Students who have studied for over two years will tend to agree that College of Business is Diverse.

The cross tabulation table as shown in Table 2 supported the above statement $(\mathrm{H} 1)$. Of 96 juniors who have completed the survey, 79 indicated that COB is diverse (with 44 agree and 35 agree strongly). At the same time, for 141 seniors who have completed the survey, 103 indicated that $\mathrm{COB}$ is diverse (with 67 agree and 36 agree strongly). In brief, majority of COB students within their junior and senior years claimed that COB is diverse.

Table 2: Crosstabulation. "College of Business (COB) is diverse?" * "What is your current standing at Ferris State University?"

\begin{tabular}{|c|c|c|c|c|c|c|c|}
\hline & & & \multicolumn{5}{|c|}{$\begin{array}{c}\text { What is your current standing at Ferris State } \\
\text { University? }\end{array}$} \\
\hline & & & Freshman & Sophomore & Junior & Senior & Total \\
\hline \multirow{4}{*}{$\begin{array}{l}\text { College } \\
\text { of } \\
\text { Business } \\
\text { (COB) is } \\
\text { diverse. }\end{array}$} & \multirow{4}{*}{$\begin{array}{l}\text { Disagree } \\
\text { Strongly }\end{array}$} & Count & 0 & 0 & 2 & 2 & 4 \\
\hline & & $\begin{array}{l}\text { \% within "College of } \\
\text { Business }(\mathrm{COB}) \text { is } \\
\text { diverse." }\end{array}$ & $0.0 \%$ & $0.0 \%$ & $50.0 \%$ & $50.0 \%$ & $100.0 \%$ \\
\hline & & $\begin{array}{l}\% \text { within "What is } \\
\text { your current standing } \\
\text { at Ferris State } \\
\text { University?" }\end{array}$ & $0.0 \%$ & $0.0 \%$ & $2.1 \%$ & $1.4 \%$ & $1.2 \%$ \\
\hline & & $\%$ of Total & $0.0 \%$ & $0.0 \%$ & $0.6 \%$ & $0.6 \%$ & $1.2 \%$ \\
\hline & \multirow[t]{4}{*}{ Disagree } & Count & 0 & 2 & 2 & 10 & 14 \\
\hline & & $\begin{array}{l}\text { \% within "College of } \\
\text { Business }(\mathrm{COB}) \text { is } \\
\text { diverse." }\end{array}$ & $0.0 \%$ & $14.3 \%$ & $14.3 \%$ & $71.4 \%$ & $100.0 \%$ \\
\hline & & $\begin{array}{l}\% \text { within "What is } \\
\text { your current standing } \\
\text { at Ferris State } \\
\text { University?" }\end{array}$ & $0.0 \%$ & $2.6 \%$ & $2.1 \%$ & $7.1 \%$ & $4.1 \%$ \\
\hline & & $\%$ of Total & $0.0 \%$ & $0.6 \%$ & $0.6 \%$ & $2.9 \%$ & $4.1 \%$ \\
\hline & \multirow[t]{2}{*}{ Neutral } & Count & 4 & 19 & 13 & 26 & 62 \\
\hline & & $\begin{array}{l}\text { \% within "College of } \\
\text { Business }(\mathrm{COB}) \text { is } \\
\text { diverse." }\end{array}$ & $6.5 \%$ & $30.6 \%$ & $21.0 \%$ & $41.9 \%$ & $100.0 \%$ \\
\hline
\end{tabular}




\begin{tabular}{|c|c|c|c|c|c|c|c|}
\hline & & $\begin{array}{l}\% \text { within "What is } \\
\text { your current standing } \\
\text { at Ferris State } \\
\text { University?" }\end{array}$ & $13.8 \%$ & $24.4 \%$ & $13.5 \%$ & $18.4 \%$ & $18.0 \%$ \\
\hline & & $\%$ of Total & $1.2 \%$ & $5.5 \%$ & $3.8 \%$ & $7.6 \%$ & $18.0 \%$ \\
\hline & Agree & Count & 13 & 32 & 44 & 67 & 156 \\
\hline & & $\begin{array}{l}\text { \% within "College of } \\
\text { Business (COB) is } \\
\text { diverse." }\end{array}$ & $8.5 \%$ & $20.5 \%$ & $28.2 \%$ & $42.9 \%$ & $100.0 \%$ \\
\hline & & $\begin{array}{l}\% \text { within "What is } \\
\text { your current standing } \\
\text { at Ferris State } \\
\text { University?" }\end{array}$ & $44.8 \%$ & $41.0 \%$ & $45.8 \%$ & $47.5 \%$ & $45.3 \%$ \\
\hline & & $\%$ of Total & $3.8 \%$ & $9.3 \%$ & $12.8 \%$ & $19.5 \%$ & $45.3 \%$ \\
\hline & Agree & Count & 12 & 25 & 35 & 36 & 108 \\
\hline & & $\begin{array}{l}\% \text { within "College of } \\
\text { Business (COB) is } \\
\text { diverse." }\end{array}$ & $11.1 \%$ & $23.1 \%$ & $32.4 \%$ & $33.3 \%$ & $100.0 \%$ \\
\hline & & $\begin{array}{l}\% \text { within "What is } \\
\text { your current standing } \\
\text { at Ferris State } \\
\text { University?" }\end{array}$ & $41.4 \%$ & $32.1 \%$ & $36.5 \%$ & $25.5 \%$ & $31.4 \%$ \\
\hline & & $\%$ of Total & $3.5 \%$ & $7.3 \%$ & $10.2 \%$ & $10.5 \%$ & $31.4 \%$ \\
\hline Total & & Count & 29 & 78 & 96 & 141 & 344 \\
\hline & & $\begin{array}{l}\text { \% within "College of } \\
\text { Business }(\mathrm{COB}) \text { is } \\
\text { diverse." }\end{array}$ & $8.4 \%$ & $22.7 \%$ & $27.9 \%$ & $41.0 \%$ & $100.0 \%$ \\
\hline & & $\begin{array}{l}\% \text { within "What is } \\
\text { your current standing } \\
\text { at Ferris State } \\
\text { University?" }\end{array}$ & $100.0 \%$ & $100.0 \%$ & $\begin{array}{c}100.0 \\
\%\end{array}$ & $\begin{array}{c}100.0 \\
\%\end{array}$ & $100.0 \%$ \\
\hline & & $\%$ of Total & $8.4 \%$ & $22.7 \%$ & $27.9 \%$ & $41.0 \%$ & $100.0 \%$ \\
\hline
\end{tabular}

$\mathrm{H} 2$ : There is a significant relationship between the respondent's profiles and whether they have done any work (within COB) on diversity and inclusion areas.

The Pearson Chi Square tests was conducted to access the relationship between the variables in $\mathrm{H} 2$. As Table 3 shows, the relation between these variables was significant, for example:

Gender $-\chi 2(2, N=349)=16.525, p<.01$.

Current Standing - $\chi 2(2, N=349)=10.081, p<.05$.

Enrollment Status $-\chi 2(2, N=349)=11.151, p<.01$.

Since the tested variables indicated the significance values are below 0.5 , the authors rejected the null hypothesis as the results support the second hypothesis $(\mathrm{H} 2)$ : There is a significant 
relationship between the respondent's profiles and whether they have done any work (within $\mathrm{COB}$ ) on diversity and inclusion areas.

Table 3: Pearson Chi-Square Analysis. "Respondent have done any work (within COB) on diversity and inclusion areas" * "respondent's profiles"

\begin{tabular}{|l|c|c|}
\hline \multicolumn{1}{|c|}{ Statement } & Value & $\begin{array}{c}\text { Asymptotic } \\
\text { Significance } \\
\text { (2-sided) }\end{array}$ \\
\hline What is your gender? (Male, Female, Transgender) & 16.525 & .000 \\
\hline $\begin{array}{l}\text { What is your current standing at Ferris State } \\
\text { University? (Freshman, Sophomore, Junior, Senior) }\end{array}$ & 10.081 & .018 \\
\hline $\begin{array}{l}\text { Please indicate your enrollment status: (Full-time, Part- } \\
\text { time) }\end{array}$ & 11.151 & .004 \\
\hline
\end{tabular}

H3: There is a significant relationship between the gender of the respondent and the COB as supportive of diversity and inclusion initiatives.

Once again, the Pearson Chi Square tests was used to test the hypothesis. The results showed the failure to reject the null hypothesis - that there is not a significant relationship between gender of the respondent and perceptions of COB supportive of any diversity and inclusion initiatives. All Person Chi-Square results for the tested variables (see Table 4) indicated the significance values are above 0.05 , for example:

Accessible to people with physical disabilities $-\chi 2(2, \mathrm{~N}=349)=15.087, \mathrm{p}>0.05$.

Supportive of people who identify as lesbian, gay, bisexual, or queer $-\chi 2(2, N=349)=12.092$, $\mathrm{p}>0.05$.

Supportive of people who identify as transgender $-\chi 2(2, N=349)=13.387, p>0.05$.

Supportive of people with diverse ethnic backgrounds $-\chi 2(2, N=349)=5.233, p>0.05$.

Supportive of international students $-\chi 2(2, \mathrm{~N}=349)=1.773, \mathrm{p}>0.05$.

Supportive of students with non-physical disabilities $-\chi 2(2, N=349)=7.415, p>0.05$.

Supportive of people with psychological disabilities $-\chi 2(2, N=349)=7.786, p>0.05$.

Hence, it is evident that gender does not have a significant impact on students' perceptions of COB supportive of diversity and inclusion initiatives.

Table 4: Pearson Chi-Square analysis. "Gender of the respondent" * "Perceptions of COB supportive of diversity and inclusion initiatives?"

\begin{tabular}{|l|c|c|}
\hline \multicolumn{1}{|c|}{ Statement } & Value & $\begin{array}{c}\text { Asymptotic } \\
\text { Significance } \\
\text { (2-sided) }\end{array}$ \\
\hline COB is accessible to people with physical disabilities. & 15.087 & .057 \\
\hline $\begin{array}{l}\text { COB is supportive of people who identify as lesbian, gay, } \\
\text { bisexual, or queer. }\end{array}$ & 12.092 & .147 \\
\hline COB is supportive of people who identify as transgender. & 13.387 & .099 \\
\hline COB is supportive of people with diverse ethnic backgrounds. & 5.233 & .732 \\
\hline
\end{tabular}




\begin{tabular}{|l|c|c|}
\hline COB is supportive of international students. & 1.773 & .987 \\
\hline $\begin{array}{l}\text { COB is supportive of students with non-physical disabilities } \\
\text { (e.g., learning disabilities, Attention Deficit Disorder). }\end{array}$ & 7.415 & .493 \\
\hline $\begin{array}{l}\text { COB is supportive of people with psychological disabilities } \\
\text { (e.g., anxiety disorders, mood disorders, depression, and } \\
\text { bipolar disorder). }\end{array}$ & 7.786 & .455 \\
\hline
\end{tabular}

(Five-point Likert scale with $1=$ disagree strongly and $5=$ agree strongly)

One of the open-ended questions asked the students "In what ways could the COB environment - including recruitment, administrative, academic, and extracurricular activities be changed to make you feel included within the broader COB community?" Some students believed that COB have done a good job in this area, for example:

- I think they do a good job making me feel included.

- I feel like if you want to be involved that's on you. Ferris does what they can.

- I personally feel very included, so nothing more needs to be done.

- I heard it was a good program, accepting of everyone.

Other students proposed that more events/activities can be organized by the COB and more promotion of the activities might be needed:

- Host more than one event, cob fest. Maybe host another event in the spring semester or provide opportunities to learn and meet other people and their cultures.

- Maybe having more 'social' events, tables throughout the day that promote and teach different things.

- Have more booths or tables with information, I am not familiar with everything the COB offers.

- Have more activities to make transgender people feel welcome and not like an outcast

- I think COB does a good job providing opportunities for students, however, the students may not attend these opportunities. It is also possible students may not be aware of all the opportunities. More PR might be needed.

- Students have to feel that international students aren't different and we need to do activities or events that have common ground.

Some students expressed concern about the faculty and staff involvement in promoting inclusion within COB:

- I can tell some professors don't give a shit about nonphysical learning disorders or stuff like anxiety problems- I'd like to see some more acceptance.

- Recognition of inclusion and some of the things professor's say to students can impact their impact on themselves. They don't need to give gold stars to every little thing, but making sure their feedback is not all negative and that there is constructive feedback as well when talking one on one with students.

- I do believe the COB also focus too much on oneself. Many times the COB faculty and staff strive to make themselves look better and instead of trying to help the student. In other words, some only help students or say they will to look better for recruitment purposes but not actually follow through with commitments.

- Tell the professors to talk to students about these events so they are known.

One final question asked the students "what are the greatest challenges to making progress on diversity and/or inclusion within COB?" Unfortunately, less than $50 \%$ of students provided responses to this question. According to some of the respondents the challenges of $\mathrm{COB}$ included: 
- People aren't open to new ideas or cultures that much.

- Students not wanting to take part in any events.

- People are still, and most likely will always be, racist. So that challenges progress.

- I guess the biggest challenges would be that there isn't a whole lot of diversity even if there is, everybody kind of just stays to themselves.

- Realizing that you can't force ignorant people to not be ignorant, if someone doesn't want to better themselves or their lives, then they won't.

- Teaching everyone -- not everyone wants to learn, so teaching people to have an open mind is the biggest challenge.

Some other students offered their perspectives on new approaches to diversity education, for example:

- Getting students to talk to each other and converse in social situations that allows students to learn about one another.

- I think that everyone has to be on board and make a really big effort in trying to make sure everyone feels welcome.

- Don't give special treatment to individuals. If everyone is equal, I don't see a need to change.

- You want to make sure the environment is open for learning without racial hate.

- Get students more involved with international students.

- To be open minded and accepting POC and LGBTQA+ and denounce white supremacists.

- It is very white. So maybe get more opportunities for experiencing different cultures.

- The initial recruitment of diverse students and their willingness to attend this college. The $C O B$ needs to ensure that everyone will feel welcome throughout their entire experience.

- Trying to get people out of the bubble and trying new things.

\section{Discussion of findings}

The findings from the first hypothesis reveal that a majority of junior and senior students perceive that the COB is diverse. This result is encouraging as it indicated that $\mathrm{COB}$ is effective in promoting diversity and inclusion to their students as a whole. While students have the opportunities to gain involvement in enhancing the diversity and inclusivity since their first few semesters within $\mathrm{COB}$, they tend to perceive that their college is diverse in the later year. This result also conforming to Brint (2015) argument where by successfully promoting personal growth and a healthy society to our business students is to produce diverse and competent citizens who can be leaders in a challenging global marketplace.

The second hypothesis findings establish a significant relationship between the participants' profiles of gender, class standing, and enrollment status and their diversity contributions on campus. Except for the factor of gender, these findings, too, are not surprising results. As previously discussed, class standing is significant because of the predominance of junior and senior level course offerings at the COB. Community college articulation also has a significant influence on the data outcomes. A review of the original responses regarding enrollment status also provide a reasonable explanation for a significant relationship. $98.27 \%$ of the respondents identified themselves as full-time students. However, a review of the original data for gender identification by respondents reveals that $52.31 \%$ identified as male, $46.82 \%$ identified as female, and the remainder identified as transgender. This raises a new question, which is addressed in the third hypothesis.

The third hypothesis asserts that there is a significant relationship between the gender of the respondent and the perceptions of the $\mathrm{COB}$ as supportive of diversity and inclusion initiatives. 
Unlike the first two hypotheses, the results of data analysis led to the acceptance of the null hypothesis. The majority of students (male, female and transgender) shared similar views of the COB's supportive role in diversity and inclusion initiatives.

This result is surprising considering that practices to create equity between male, female, and especially transgender students are in a continuing state of evolution (Butler, 2018; Tatum, 2018). Furthermore, Thelin (2011) noted that, "the commitment to increasing education opportunities for women [does] not entail a commitment to reducing discrimination." (p. 227). Our country's history illustrates that diversity practices do not ensure an inclusive culture. It is encouraging, then, to discover that gender did not influence the findings, and the research population shared similar views on this topic.

All three hypotheses reveal that students enrolled in programs at the COB are aware of diversity and inclusion initiatives at the college, as well as throughout the university. Furthermore, a majority of students positioned as juniors and seniors believe that they have made a contribution involving diversity and inclusion during their time with the university. These positive indicators underscore the successful efforts of the COB to address these matters.

This is not to say that the COB has done enough in this area. The responses make it clear that there is room for improvement, and current programs should be constantly reviewed for effectiveness. It is also an opportunity to look beyond our campus and learn about diversity and inclusion initiatives at community colleges, which may have the ability to lay the groundwork for student competency in this area. Ultimately, collaborative measures can be taken at the administrative and instructional levels to emphasize the importance of diversity and inclusion and promote awareness programs.

\section{Limitations and future research}

Methodology is the foundation of research (Saunders, Lewis \& Thornhill, 2000). Because quantitative research measures the perspectives of a sample population in order to make generalizations to a larger population, it can be reasonably expected that limitations will occur beyond our control. We have identified two potential limitations to our descriptive study that need to be addressed.

First, the survey was conducted over a relatively short period (one week), so the sample size may have been restricted. If there had been more time for data collection, more respondents might have completed the survey. Second, almost half of the COB student enrollment came from rural locales. As a result, they may have lacked the exposure to inclusion experiences that students from larger, more culturally sophisticated environments have encountered. This second limitation has more significant implications than the first. Students with limited access to diverse cultures and populations may perceive that any initiative, regardless of size or quality, is a grand gesture. This is a good example where ignorance is not bliss; Ignorance is ignorance, and has potential to limit the value of the research.

As previously mentioned, the research is limited on this topic. The results of the study added to our knowledge of business students' perceptions of COB diversity initiatives at FSU. In particular, it brought our attention to the factor of community college articulation and gender perceptions, and the need to perform more research on both.

The results of our research required us to accept the null hypothesis because it was evident that gender did not have a significant impact on students' perceptions of the COB as supportive of diversity and inclusion initiatives. However, a study that separately analyzes the perspectives of our male and female students has value. It is important to discover that the 
COB is perceived as being supportive of diversity and inclusion efforts. However, why it is perceived in that light could provide ideas for more targeted initiatives. It may be that a study of this nature, where data is gathered specifically from our gender populations, may offer opportunities to provide specific areas of interest that are unique to our male, female and transgender populations.

As the literature reveals, diversity and inclusion education is no longer an option, an elective program that students can choose to avoid. Future post-graduate success depends on each student possessing the ability to be respectful and communicate in a variety of environments. Continued research on this subject including across disciplines and workforce areas will provide a springboard to creative problem solving for an evolving world.

\section{References}

Babin, B.J. Zikmund, W.G. (2016). Essentials of Marketing Research 6th edition. Boston, MA: Cengage Learning.

Brint, S. (2015). The Multiple Purposes of an Undergraduate Education. Riverside, CA: University of California, Berkeley.

Brunner, B.R. (2006). 'Student perceptions of diversity on a college campus: Scratching the surface to find more', Intercultural Education, 17(3), 311-317.

Butler, J. (2018). Building nests in another windy place - The diversity imperative in higher education in the United States. In: S. Bergan \& I. Harkavy (Eds.), Higher Education for Diversity, Social Inclusion and Community: A Democratic Imperative (pp. 75-86). Strasbourg, Cedex: Council of Europe Publishing.

Chang, M.J., Astin, A.W. \& Kim, D. (2004). 'Cross-racial interaction among undergraduates: Some consequences, causes, and patterns', Research in Higher Education, 45(5), 529-553.

Chang, M.J., Denson, N., Saenz, V. \& Misa, K. (2006). 'The educational benefits of sustaining cross-racial interaction among undergraduates', Journal of Higher Education, 77(3), 430-455.

College of Business. (n.d.). About the College of Business. Retrieved from http://ferris.edu/business/about/

Creative Research Systems. (n.d.). Sample Size Calculator. Retrieved from https://www.surveysystem.com/sscalc.htm

Etsy, K., Griffin, R. \& Schorr-Hirsh, M. (1995). Workplace diversity: A Manager's Guide to Solving Problems and Turning Diversity into a Competitive Advantage. Holbrook, MA: Adams Media Corporation.

Ferris State University (n.d.). Ferris State University a Top Michigan College. Retrieved from http://www.ferris.edu/top-rated-best-colleges-and-universities-in-michigan.htm

Green, K.A., Lopez, M., Wysocki, A. \& Kepner, K. (2002). 'Diversity in the workplace: Benefits, challenges, and the required managerial tools', University of Florida IFAS Extension, HR022, 1-3.

Hair, J.F., Celsi, W.C., Ortinau, D.J. \& Bush, R.P. (2017). Essentials of Marketing Research, 4th edition. New York, NY: McGraw-Hill.

Hakkola, L. \& Ropers-Hullman, R (2018). A critical exploration of diversity discourses in higher education: A focus on diversity in student affairs and admissions. In M.B. Paulsen \& L.W. Perna (Ed.), Higher Education: Handbook of Theory and Research (pp. 417468), lowa City, IA: Springer.

Ho, H.W.L. (2017). 'International students' perceptions of services and supports provided: A case study of a mid-sized university in the USA', International Journal of Technology and Educational Marketing, 7(11), 1-14.

Hurtado, S., Milem, J.M., Clayton-Pedersen, A.R. \& Allen, W.R. (1998). 'Enhancing campus climates for racial/ethnic diversity: Educational policy and practice', Review of Higher Education, 21(3), 279-302. 
Israel, G.D. (1992). 'Determining sample size. University of Florida Cooperative Extension Service, Institute of Food and Agriculture Sciences, EDIS, Florida. Retrieved from https://www.tarleton.edu/academicassessment/documents/Samplesize.pdf

Jayakumar, U.M. (2008). 'Can higher education meet the needs of an increasingly diverse and global society? Campus diversity and cross-cultural workforce competencies', Harvard Educational Review, 78(4), 615-651.

Kwak N., Gavrila G.S. \& Ramirez F.O. (2019). Enacting diversity in American higher education. In: T. Christensen, A.. Gornitzka \& F.O. Ramirez (eds), Universities as Agencies: Reputation and Professionalization (pp. 209-228). New York, NY: Palgrave Macmillan.

Managuio, M. (2013). Campus climate: Perceptions of diversity among students at Virginia Tech.Philologia, $\quad V, \quad 12-18 . \quad$ Retrieved from https://vtechworks.lib.vt.edu/bitstream/handle/10919/47581/journal_2013.pdf?seque nce $=1$

Miller, F.A. \& Katz, J.H. (2002). The inclusion breakthrough: Unleashing the Real Power of Diversity. San Francisco, CA: Berrett-Koehler.

Mor Barak, M.E. (2014). Managing diversity: Toward a globally inclusive workplace, $3^{\text {rd }}$ edition. Thousand Oaks, CA: Sage Publications.

Mor Barak, M.E., Cherin, D.A. \& Berkman, S. (1998). 'Organizational and personal dimensions in diversity climate', Journal of Applied Behavioral Science, 34(1), 82-104.

Norman, M., Chang, P. \& Prieto, L. (2017). 'Simulating critical thinking in U.S. business students through the inclusion of international students', Journal of Business Diversity, 17(1), 122-130.

Roberson, Q. (2006). 'Disentangling the meanings of diversity and inclusion in organizations', Group and Organizational Management, 31(2), 212-235.

Sarmah, H.K., Hazarika, B.B. \& Choudhury, G. (2013). 'An investigation on Effect of Bias on Determination of Sample Size on the Basis of Data Related to the Students of Schools of Guwahati', International Journal of Applied Mathematics and Statistical Sciences (IJAMSS), 2(1), 33-48.

Saunders, M., Lewis, P. \& Thornhill, A. (2000). Research methods for business students. Harlow: Pearson Education Limited.

Silver, L.S., Stevens, R., Kernek, C., Wrenn, B. \& Loudon, D. (2016). The Essentials of Marketing Research 4th edition. St Paul, MN: Textbook Media Press.

Singh, A.S. \& Masuku, M.B. (2014). 'Sampling techniques \& determination of sample size in applied statistics research: An overview', International Journal of Economics, Commerce and Management, I/(11). Retrieved from: http://ijecm.co.uk/wpcontent/uploads/2014/11/21131.pdf

Smith, D.G. (2015). Diversity's Promise for Higher Education: Making It Work. Baltimore, MD: The Johns Hopklns University Press.

Sumner, S.W., Sgoutas-Emch, S., Nunn, L. \& Kirkley, E. (2017). 'Implementing innovative pedagogy and a rainbow curriculum to expand learning on diversity', Insight: A Journal of Scholarly Teaching, 12, 94-119.

Tatum, B. (2018). Identifying inclusive practices on U.S. university campuses that create engagement for diverse population (Doctoral dissertation). Retrieved from Abilene Christian University (Paper 116).

The Ferris State University (n.d.). Fact Book 2016 - 2017. Retrieved from https://ferris.edu/admissions/testing/factbook/FactBook16-17-4.pdf

Thelin, J.R. (2011). A History of American Higher Education, 2nd edition. Baltimore, MD: The Johns Hopklns University Press.

Yamane, T. (1967). Statistics, An Introductory Analysis, 2nd edition. New York, NY: Harper and Row.

Zikmund, W., D'Alessandro, S., Winzar, H., Lowe, B. \& Babin, B.J. (2014). Marketing Research: 3rd Asia-Pacific Edition. Melbourne, Victoria: Cengage Learning Australia. 


\section{Biographical Notes}

Henry Ho is an Associate Professor of Marketing at Ferris State University. Henry's research focuses on customer value creation and delivery in the B2B context, marketing in Asia, international advertising and promotion and marketing education. Dr. Ho has over 40 peerreviewed publications in journals and proceedings. He received his Doctor of Business Administration degree from Southern Cross University in Gold Coast, Australia.

Catherine Browers has been a professor in the College of Business at Ferris State University since 2007. Dr. Browers has taught courses in topics of financial and managerial accounting, financial management, ethics and fraud, management and associated metrics, small business systems, and entrepreneurship. She has received several awards and honourable mentions for her university and private sector work. 